\title{
JUURNAL.RU
}

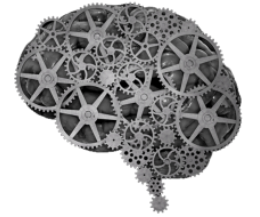

COMPANY GROUP "INTELLEKT"

Дергунова Е.Е. Самарский государственный архитектурно-строительный университет Самара, Россия

doi: 10.18411/1j2016-5-2-07

\section{Структура профилей информационных систем}

Ключевые слова: Информационная система, ссылки,стандарты, профиль системы, жизненный цикл информационной системы.

Разработка и применение профилей являются органической частью процессов проектирования, разработки и сопровождения информационных систем. Профили характеризуют каждую конкретную ИС на всех стадиях её жизненного цикла, задавая согласованный набор базовых стандартов, которым должна соответствовать система и её компоненты.

Стандарты, важные с точки зрения заказчика, должны задаваться в техническом задании на проектирование системы и составлять её первичный профиль. То, что не задано в техническом задании, первоначально остается на усмотрение разработчика системы, который, руководствуясь требованиями технического задания, может дополнять и развивать профили системы и впоследствии согласовывать их с заказчиком. Таким образом, профиль конкретной системы не является статичным, он конкретизируется и развивается в процессе проектирования ИС и оформляется в составе документации проекта системы.

В профиль конкретной системы включаются спецификации компонентов, разработанных в составе данного проекта, и спецификации использованных готовых программных и аппаратных средств, если эти средства не 
специфицированы соответствующими стандартами. После завершения проектирования и испытаний системы, в ходе которых проверяется её соответствие профилю, профиль применяется как основной инструмент сопровождения системы при эксплуатации, модернизации и развитии.

Формирование и применение профилей конкретных ИС выполняется на основе международных и национальных стандартов, ведомственных нормативных документов, а также стандартов де-факто при условии доступности соответствующих им спецификаций. Для обеспечения корректного применения профилей их описания должны содержать:

- определение целей использования профиля;

• точное перечисление функций объекта или процесса стандартизации;

- формализованные сценарии применения базовых стандартов и спецификаций, включенных в профиль;

- сводку требований к ИС или к её компонентам;

- нормативные ссылки на конкретный набор стандартов и других нормативных документов, составляющих профиль, с точным указанием применяемых редакций и ограничений;

- информационные ссылки на все исходные документы. 


\section{Литература:}

1. Дергунова Е.Е, разработка программного обеспечения информационных систем при помощи CASE-средств /Дергунова Е.Е., Тимофеев А.В., Козлов В.В. // Наука и образование в современном мире: сб.науч.тр. - Москва,2016.

2. ДергуноваЕ.E,RapidApplicationDevelopment/Дергунова Е.Е., Тимофеев А.В., Козлов В.В.// Наука и образование в современном мире: сб.науч.тр. Москва,2016.

3. Липаев В. В. Направления развития методов и стандартов открытых систем. Информатика и вычислительная техника. Научно-технический сборник. Выпуск 1-2. М. 1995 г.

4. Лезер Н. Архитектура открытых распределенных систем: Модель OSF DCE. Открытые системы. № 3, 1993.

5. Филинов Е. Н. Выбор и разработка концептуальной модели среды открытых систем. Открытые системы. № 6, 1995. 